\title{
Intrahepatic bile duct stone treatment combining electrohydraulic lithotripsy and peroral cholangioscopy through a choledochoduodenal fistula
}

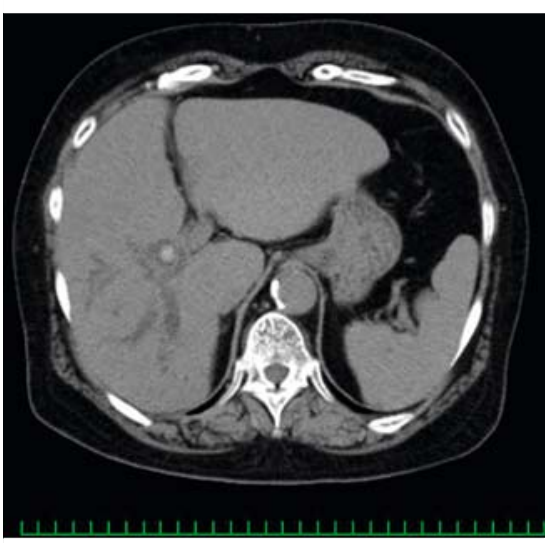

- Fig. 1 Computed tomography reveals intrahepatic bile duct stones in a 62-yearold woman with cholangitis symptoms.
A 62-year-old woman with intrahepatic bile duct stones ( $\vee$ Fig. 1 ) and cholangitis symptoms was admitted to the hospital. She had undergone cholecystectomy 12 years previously for cholelithiasis. We performed endoscopic retrograde cholangiopancreatography (ERCP) to relieve her symptoms and reduce inflammation. Duodenoscopy showed an approximately 2-mm fistula in the duodenal bulb; guidewire placement and radiography confirmed a choledochoduodenal fistula. We performed balloon dilation of the choledochoduodenal fistula using a 6-mm balIoon catheter (REN; Kaneka Medical Products, Tokyo, Japan). A single-operator fi- beroptic cholangioscope direct visualization device (SpyGlass DS; Boston Scientific Corporation, Marlborough, Massachusetts, USA) was inserted over the guidewire into the intrahepatic bile duct under radiographic guidance, and all intrahepatic bile duct stones and debris were crushed via electrohydraulic lithotripsy (EHL). Finally, a 7-Fr plastic stent was inserted into the choledochoduodenal fistula ( $\triangleright$ Fig. 2 and $>$ Fig. 3; Video 1 ). Postoperative recovery was quick.

Peroral cholangioscopy has been used to diagnose and treat biliary diseases since the 1970s [1]. The SpyGlass system has been available since 2005 [2], and the
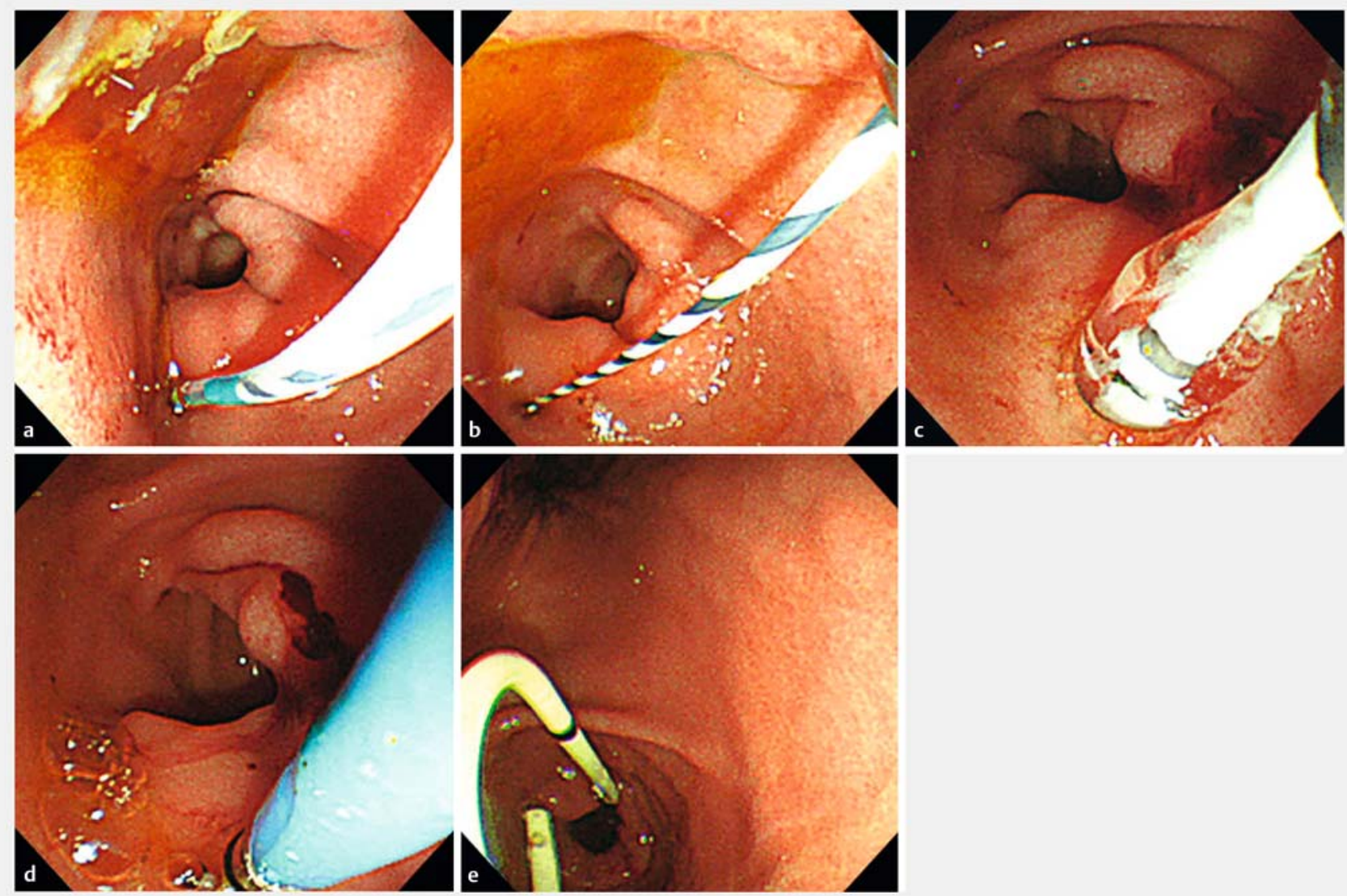

- Fig. 2 a Choledochoduodenal fistula in the interior wall of the duodenal bulb. b Guidewire placement into the choledochoduodenal fistula using a duodenoscope. $\mathbf{c}$ Balloon dilation of the fistula. $\mathbf{d}$ Insertion of a SpyGlass DS device into the intrahepatic bile duct. e Placement of a plastic stent into the choledochoduodenal fistula using a duodenoscope. 

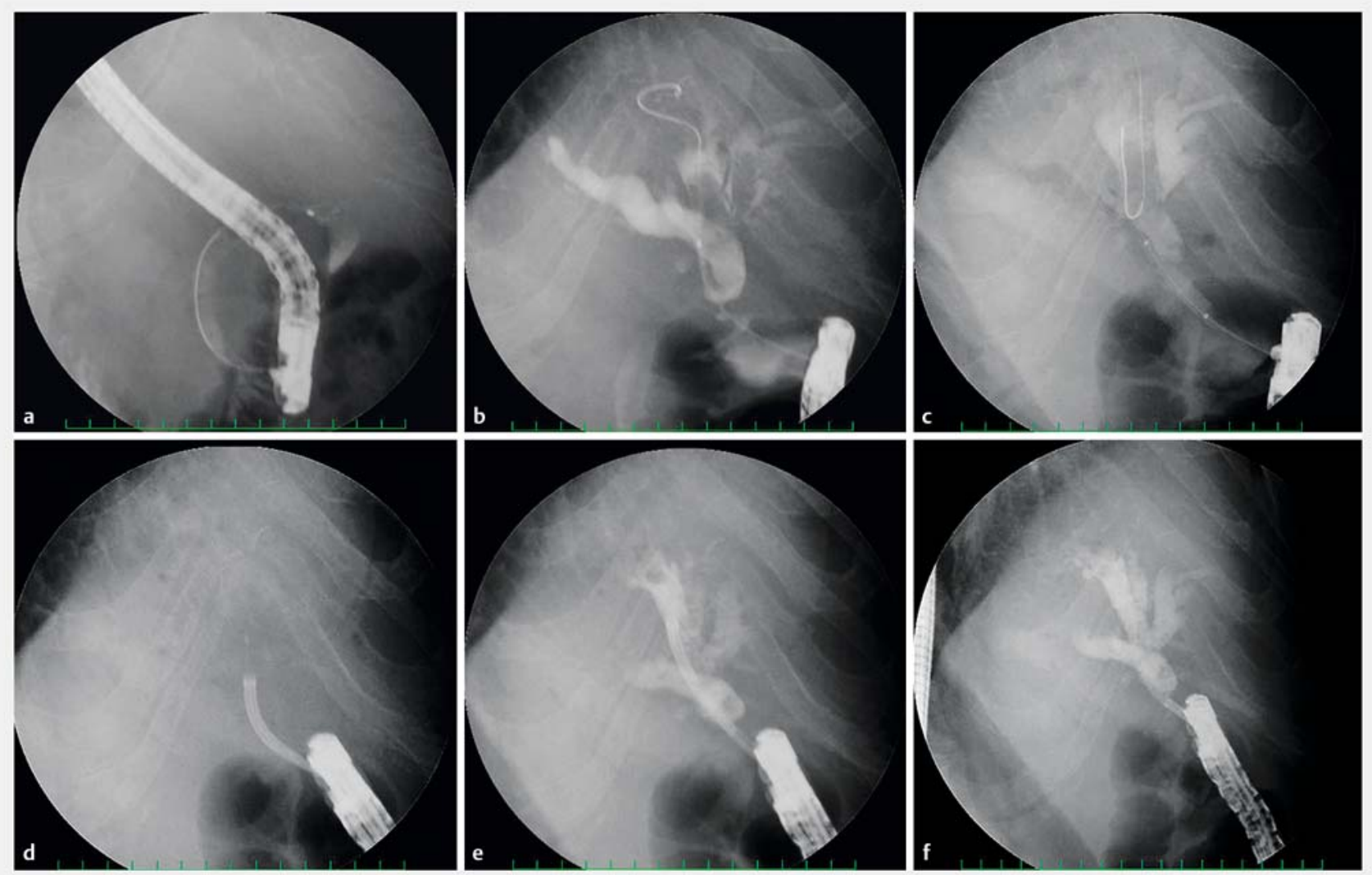

- Fig. 3 Cholangiography images with duodenoscope. a A choledochoduodenal fistula. b Intrahepatic bile duct stones. c Balloon dilation of the choledochoduodenal fistula. $\mathbf{d}$ Insertion of a SpyGlass DS into the intrahepatic bile duct. e Crushing stones and debris with electrohydraulic lithotripsy (EHL). f Intrahepatic bile duct stones have been cleared using a SpyGlass DS with EHL.

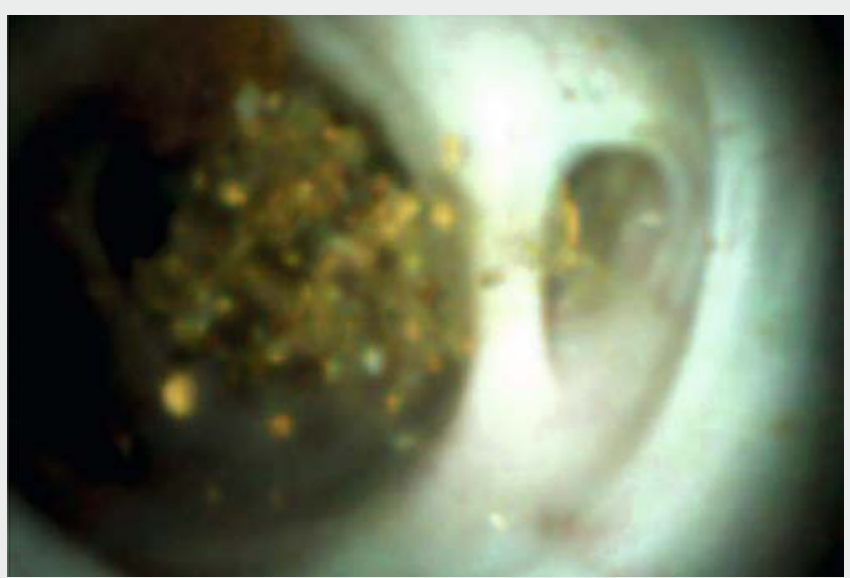

$\checkmark$ Video 1 Intrahepatic bile duct stones and debris are crushed using electrohydraulic lithotripsy and SpyGlass DS. second-generation SpyGlass DS, with better images, ergonomics, stability, and accessory exposure, and a larger working channel and clinical utility for diagnosis and therapy in biliary diseases, was introduced in 2014 [3,4]. This case highlights the benefits of using SpyGlass DS with EHL in patients with a choledochoduodenal fistula and complicated cholelithiasis.

Endoscopy_UCTN_Code_TTT_1AR_2AH

Competing interests

None 
The authors

Ryuichi Yamamoto ${ }^{1}$, Toshiyuki Abe ${ }^{2}$, Shosuke Hosaka $^{3}$, Takayoshi Akase ${ }^{4}$, Ayasa Ito ${ }^{5}$, Mikio Kawayama ${ }^{1}$, Kazunao Watanabe ${ }^{6}$

1 Department of Gastroenterology, TokyoWest Tokushukai Hospital, Tokyo, Japan

2 Department of Gastroenterology, Saitama Sekishinkai Hospital, Saitama, Japan

3 Department of Gastroenterology, Chibanishi Grand Hospital, Chiba, Japan

4 Department of Surgery, Tokorozawa Proctology Hospital, Tokyo, Japan

5 Endoscopy Center, Tokyo-West Tokushukai Hospital, Tokyo, Japan

6 Department of Surgery, Tokyo-West Tokushukai Hospital, Tokyo, Japan

Corresponding author

Ryuichi Yamamoto, MD, PhD

Tokyo-West Tokushukai Hospital, Department of Gastroenterology, 3-1-1, Matsubara, Akishima, Tokyo 159-0003, Japan

Fax: +81-42-5006632

ryuichi5118@gmail.com

\section{References}

[1] Ghersi S, Fuccio I, Bassi M et al. Current status of peroral cholangioscopy in biliary tract diseases. World J Gastrointest Endosc 2015; 7: $510-517$

[2] Parsi MA. Peroral cholangioscopy in the new millennium. World J Gastroenterol 2011; 17: $1-6$

[3] Franzini TAP, Moura RN, Moura EG. Advances in therapeutic cholagioscopy. Gastroenterol Res Pract 2016. doi:10.1155/2016/ 5249152

[4] Ogura T, Imanishi M, Kurisu Y et al. Prospective evaluation of digital single-operator cholangioscope for diagnostic and therapeutic procedures (with videos). Dig Endosc 2017; 29: $782-789$

\section{Bibliography}

DOI https://doi.org/10.1055/a-0914-2581

Published online: 23.5.2019

Endoscopy 2019; 51: E290-E292

(c) Georg Thieme Verlag KG

Stuttgart · New York

ISSN 0013-726X

\section{ENDOSCOPY E-VIDEOS}

https://eref.thieme.de/e-videos

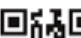

Endoscopy E-Videos is a free

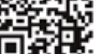
access online section, reporting on interesting cases and new techniques in gastroenterological endoscopy. All papers include a high quality video and all contributions are freely accessible online.

This section has its own submission website at https://mc.manuscriptcentral.com/e-videos 